2010-07-02

\title{
Bite Size Oral Health Promotion
}

\section{Witton, Robert}

http://hdl.handle.net/10026.1/18299

10.12968/denu.2010.37.6.382

Dental Update

Mark Allen Group

All content in PEARL is protected by copyright law. Author manuscripts are made available in accordance with publisher policies. Please cite only the published version using the details provided on the item record or document. In the absence of an open licence (e.g. Creative Commons), permissions for further reuse of content should be sought from the publisher or author. 


\section{DentalPublicHealth}

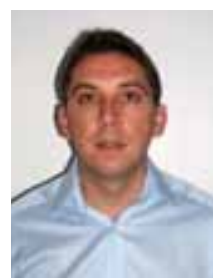

Robert Witton

\section{Bite Size Oral Health Promotion}

Abstract: Improving health is part of the Government's wider public health agenda and central to this theme is the requirement to help patients make informed healthy choices. The aim of the article is to review the basis of oral health promotion in primary dental care, explain why it is necessary and to give some practical tips on behaviour change in practice.

Clinical Relevance: Understanding and relating well to your patients can make oral health promotion more successful, with communication skills being paramount in achieving this goal, along with the creation of a supportive health-orientated practice environment.

Dent Update 2010; 37: 382-388

As dental professionals we all recognize the importance of oral health promotion, but do we really understand what it means or how to do it? More importantly, do our efforts actually result in our patients adopting healthy lifestyles and achieving oral health over the course of their lives? The Department of Health in the UK has indicated a desire to move the NHS (including dentistry) from a 'treatment service' to a 'health promoting service.' This shift is part of a wider Government agenda to promote general health and well-being and reduce health inequalities.

\section{The health divide}

Health inequality can help to explain why dental disease is unacceptably high in many communities against a back-drop of nationwide improvements in oral health. Furthermore, there is growing evidence that the health divide is actually increasing. ${ }^{2}$ It is first important to recognize oral health as an indistinguishable component of general health, and many of the factors which

Robert Witton, BDS, DPDS, MFDS RCS(Eng), MFGDP(UK), CertPerio, Specialist Registrar in Dental Public Health, Peninsula Dental School, The John Bull Building, Tamar Science Park, Plymouth PL6 8BU, UK. contribute to general health equally apply to the oral cavity. These differences arise from the poor social and environmental circumstances in which patients live and may indirectly affect health behaviour or directly affect biological functioning, leading to ill health. Identifying and tackling the social stresses that result in poor health experiences is complex but, in general terms, social gradients have been attributed to material, behavioural, environmental and psycho-social characteristics. ${ }^{3}$ Such factors play a key role in determining health outcomes. Factors which may contribute to poor health are summarized in Table $1 .{ }^{4}$

If we accept the premise of social gradients, individual responsibility for disease (or ill health) is limited and, instead, public health measures are required to support communities to achieve health. It is all too easy to become disillusioned with oral health promotion and blame the patient for not following your expert preventive advice. But, having some appreciation of the way patients lead their lives and why is fundamental to success. In fact, the contribution dental care can make to self esteem, confidence and quality of life is probably underestimated.

\section{What do we mean by health?}

If we are attempting to promote and improve oral health we must first understand what health means. This is where it becomes problematic as health and disease are complex issues which are difficult entities to define. The World Health Organization defines health as a complete state of physical, mental and social well-being and not merely the absence of disease and infirmity. ${ }^{5}$ Many now believe this definition is too simplistic and a much greater focus on the individual's subjective experience of his/her functional, social and psychological well-being is a more appropriate way of defining his/her health needs. ${ }^{6}$ In other words, health is also an expression of a functional position in society as much as it is being free from a disease. It is important to recognize that improving oral health is more than just providing treatment. Simply filling a carious tooth without giving any advice as to why the cavity occurred in the first place does not eliminate the disease. At a first glance, this appears obvious, but oral health can be a difficult concept for many of us to grasp, as we have been trained to seek and treat disease, and are financially rewarded for doing so. However, converting to a health promoting or preventively-orientated practice does not have to be onerous or financially draining. promotion involve? 


\begin{tabular}{|l|l|l|}
\hline Lifestyle factors & $\begin{array}{l}\text { Age } \\
\text { Sex } \\
\text { Genetic } \\
\text { background } \\
\text { Diet }\end{array}$ & $\begin{array}{l}\text { Exercise } \\
\text { Smoking } \\
\text { Alcohol consumption } \\
\text { High-risk behaviour }\end{array}$ \\
\hline Social \& Cultural Factors & $\begin{array}{l}\text { Family, friend \& peer support } \\
\text { Cultural norms \& traditions } \\
\text { Community participation/engagement } \\
\text { Social capital }\end{array}$ \\
\hline Environmental factors & $\begin{array}{l}\text { Educational opportunities } \\
\text { Housing (water, sanitation, heating, etc) } \\
\text { Work-place environment } \\
\text { Community facilities, open spaces, etc } \\
\text { Crime levels } \\
\text { Healthcare services }\end{array}$ \\
\hline Socio-economic factors & $\begin{array}{l}\text { Employment } \\
\text { Income level } \\
\text { Deprivation levels in the community } \\
\text { Immigration status } \\
\text { Long-term illness, disability, etc }\end{array}$ \\
\hline
\end{tabular}

Table 1. Factors which may contribute to poor health (adapted from Dahlgren \& Whitehead 19914).

\section{Creating supportive environments}

This emphasizes that health cannot be separated from other goals in society. It suggests that health promotion must generate living and working conditions that are safe, stimulating, satisfying and enjoyable. In doing so, these environments are conducive to health.

\section{Building healthy public policy}

Health promotion goes beyond healthcare. It must be on the agenda for all policy makers so that obstacles to the adoption of healthy lifestyles can be removed. Policy must ensure healthy choices are easy choices.

\section{Strengthening community action}

Health can only be improved and maintained through community and individual actions. Empowerment gives communities ownership and control of their endeavours and destinies. To enable this, professionals have an important supporting role in providing information and resources.

\section{Developing personal skills}

Health promotion supports personal and social development through providing information, education for health and by developing skills to make choices conducive to health.

\section{Re-orientating health services}

The responsibility for health promotion is shared by health services, individuals, community groups, professionals, health institutes and governments. Improvement in health requires a change in attitude and shift in services, skills, personnel and facilities towards health promotion and prevention.

Table 2. Ottawa Charter $1986 .{ }^{8}$
Oral health promotion aims to achieve a sustainable improvement in oral health and reduce inequalities through actions directed at the determinants of health. ${ }^{7}$ It is often confused with oral health education but a key feature of oral health promotion is the requirement for communities, organizations and political systems to work together in tackling these underlying causes. This type of action is described as upstream and aims to improve the conditions in which people live, enabling them to make healthy choices. In contrast, health education is a downstream approach as it is aimed at individuals and their actions.

An example of the two different approaches is to consider a family living in a deprived community with no car and poor dietary habits. Oral health education from the dental team would advise the family to limit the consumption of snack food and confectionery and promote the intake of fresh fruit and vegetables. This is entirely reasonable if there are sufficient (if any) retailers selling fresh produce at a reasonable price in the local area. If not, the advice is difficult to follow. The upstream approach would be to ensure these choices are easy and accessible through community development and action. Community empowerment aims to help people find the solution to their own problems and take ownership of their health. Despite being published over 20 years ago, the Ottawa Charter (Table 2) still provides a relevant and useful framework for guiding health promotion activities. $^{8}$

\section{What can dental practices do?}

At this stage, it can appear that much of this theory is remote from managing patients on a daily basis in practice. Aside from the ethical and moral obligations of providing advice for patients in order to achieve oral health (even if you think it will not be used), dental teams are well positioned in the community to offer health promotion interventions.

Regardless of the environment in which you work, every 
reader will have a population of patients with very different needs. Within this community there will be groups or individuals that warrant particular oral health promotion activities. A few examples include smokers, deprived families, pregnant women, medically compromised patients, the elderly and individuals displaying highrisk behaviour. Young children are particularly vulnerable to poor health practices as they are directly under parental control. Establishing good oral health practices from an early age is paramount if long-term oral health is to be achieved. This will also benefit the wider family unit and help break down the social pattern of dental disease. Preventive dental visits should be encouraged from an early age as there is growing evidence that poor health outcomes in childhood can directly affect health in later life. This is especially true for early childhood caries. ${ }^{9}$

There are many individuals with specific health needs and dental professionals are well placed to identify them and target resources appropriately. One way of doing this is to assign the patient to a risk category. This approach can help to focus the attention of the dental team on those with the greatest health need, ensuring that they receive the time and support they require. It will also inform how frequently the patient should be seen in accordance with NICE guidelines. ${ }^{10}$ It is worthwhile remembering that risk can change throughout life. It can be affected by adverse life events such as redundancy, bereavement, illness, or family and work pressures. Oral health needs may also change as a result of medical conditions, immobility or ageing. By focusing on the individual as a person, the clinician may be much more responsive to his/ her specific needs, and much better equipped to offer timely and effective support. Targeted action does have its critics but this high-risk approach does not mean that the other patients have to miss out. Both population and high-risk approaches can work together in practice to harness all available opportunities for health improvement. This is a worthwhile investment and a vital part of building healthy

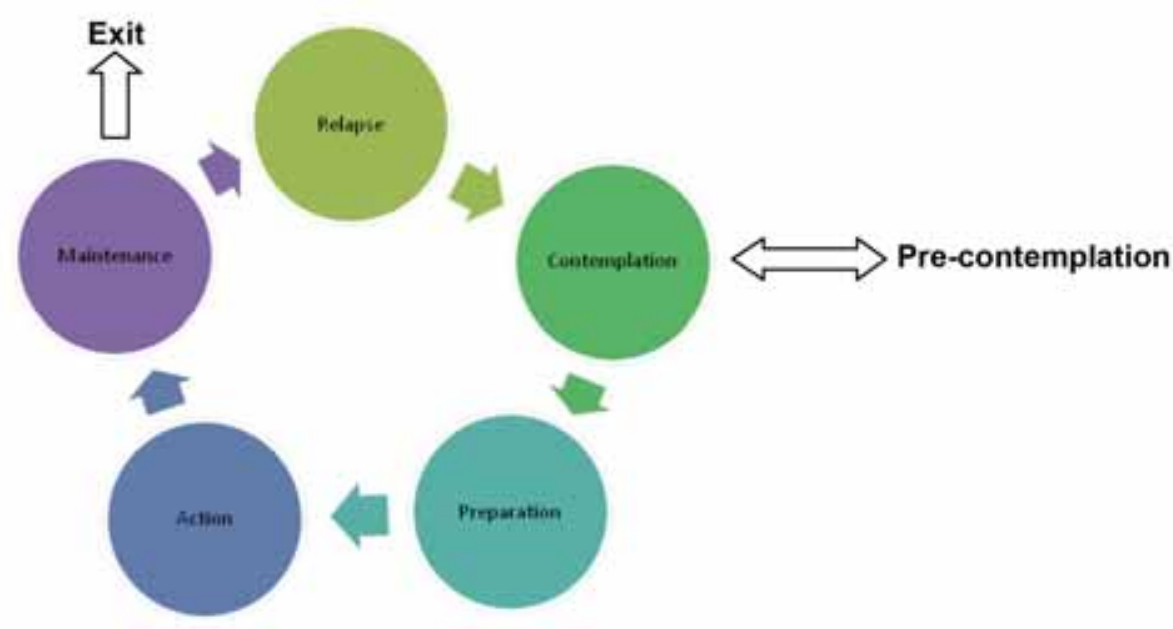

Figure 1. Transtheoretical model of behaviour change (Prochaska and DiClemente ${ }^{12}$ ).

public policy. The problem with these interventions can be that results are not quite so obvious and immediate to the dental team. Nevertheless, it can result in small, albeit important, improvements in population health over time.

\section{Key oral health messages}

When discussing oral health at the chair-side, or when incorporating oral health into a practice strategy, there are several key messages to promote to patients:

- Optimal fluoride use;

Effective self-care;

Dietary advice to reduce sugar intake;

- Healthy eating;

Awareness and acceptance of regular preventive dental care;

- Smoking cessation advice;

- Alcohol reduction advice;

- Dental injury prevention. The aim of oral health promotion is to give clear and concise information in a way that individuals or groups can use without being threatened or confused. This has been one of the problems for oral health promotion in the past. Such advice was often given in isolation to wider health issues and artificially separated the mouth from the rest of the body. It is now recommended that oral health advice is complementary to general public health campaigns. These may be local, regional or national policies and dental teams are best placed to know the local needs of the communities they serve. Risk factors for oral disease, such as poor oral hygiene, diets high in sugar, abnormal eating patterns or habits, tobacco use and excessive alcohol consumption, are linked to heart diseases, diabetes, obesity and cancerrelated deaths. The common risk factor approach $^{11}$ aims to include oral health promotion as an integral component of general lifestyle advice and it can provide extra leverage when discussing risk factor reduction with the patient.

\section{The concept of change}

Traditionally, chair-side oral health promotion has been about getting the patient to change some behaviour which is either harmful or misdirected, but a more relevant question might be to ask why the behaviour occurs in the first instance. Understanding the reasons why and working in partnership with the patient to solve the problem may be a more successful route. Take the example of a single working mother with four young children. She tries her best to ensure that all her children's teeth are clean before bedtime but is shattered herself and doesn't always manage it. A few practical tips and advice on effective toothbrushing could help enormously, 
but without some knowledge of her social circumstances she could be dismissed as being unmotivated.

There is evidence that behaviour change occurs in steps and that movement through these stages is cyclical and dynamic. Expecting immediate and direct behaviour change is far too simplistic. It is more likely to occur in a spatial manner of adoption of the new behaviour, maintenance, relapse and re-adoption over time. Relapse is not failure and patients should not be made to feel that this is the case. Instead, it is a normal and, hopefully, momentary state in the process of change. Prochaska and DiClemente ${ }^{12}$ have described the dynamics of behaviour change as five distinct stages (Figure 1). This transtheoretical, or stages of change, model has been most commonly applied to smoking cessation but is equally valid to any change in behaviour which is either self-directed or clinically driven.

Imagine a patient wishing to change some behaviour. Before he/she even considers change on the horizon he/she exists in a pre-contemplation stage. At this point, the individual has not considered the change, might not consider the change possible, or may not even be interested in changing. Nevertheless, information is gathered all of the time from multiple sources and probably subconsciously. Something then happens to prompt the person to consider change - the contemplation phase. Perhaps talking to a member of the dental team, a local health campaign or sharing experiences with a family member or friend may trigger the individual to reflect on his/her own circumstances. The contemplation phase is the entry point into the change process and is an ideal opportunity for health promotion when the individual is primed to listen and accept advice. The person then prepares to make the change - the preparation phase. It may coincide with another event, for example giving up smoking on a birthday, being co-ordinated with a friend trying to do the same or being linked to another lifestyle change, exercise and healthy eating being one such example. The action phase is a crucial period when the person modifies the behaviour. During this time he/she is evaluating the risks/benefits of the change and measuring the impact on his/ her life. The momentum at this stage can be lost if the individual finds the change too impractical, being still unsure of the benefits or lacking family, friend or peer support. Motivation and encouragement at this point can overcome these barriers and propel the individual into maintenance. It is more likely to be successful if the new behaviour is incorporated into the normal routine of daily living and positively associated with another event or action. In the author's experience, if a periodontal patient needs to perform complex oral hygiene procedures, compliance is likely to be improved if he/she sets aside time during a favourite radio or television show rather than last thing before bed or before work. Similarly, do not assume that the patient can master these and other techniques after only one appointment of instruction. This is totally unrealistic and counterproductive. Just as we need time to develop our skills, so do our patients. Prochaska and DiClemente found that smokers went around the wheel between three and seven times before they quit for good. ${ }^{12}$ This underlines the fact that relapse is a normal part of the change process and patients should be encouraged to re-enter the cycle rather than being reprimanded. A team approach is essential to share and develop the variety of communication and inter-personal skills necessary to support patients at different stages of change. It is estimated that at any one time in a population there are $40 \%$ of individuals in pre-contemplation, $40 \%$ in contemplation and $20 \%$ in preparation for some behaviour change..$^{13}$ One study investigated the use of this model in smokers waiting for referral to a periodontal clinic for treatment. They found that $31 \%$ were in pre-contemplation of quitting, $46 \%$ in contemplation and $23 \%$ were in preparation. ${ }^{14}$ Furthermore, nearly half of referred smokers wished to quit smoking alongside their periodontal treatment. It is evident that dental teams have access to a significant proportion of society willing to make healthy choices with the right type of advice and support. In this respect, primary dental care workers can be important health advocates.

It is important to recognize that behaviour modification is a complex and contentious subject and that the model described above is one of many. Despite this, it is a useful framework to open dialogue with the patient and emphasizes the fact that change is a cyclical rather than a linear event. In this respect, it can help practitioners manage behaviour change in a non-judgemental and supportive way.

\section{Some tips on behaviour change}

- Recognize the patient as an individual and tailor your advice appropriately;

Keep you message clear, concise and consistent;

- Remember that interpersonal skills are vital to communicating the right message in the right way;

Set realistic targets which the patient can achieve. Breakdown the journey into small steps;

- If you want the patient to develop a new skill, he/she needs to be taught it at a personal level;

Don't give up after the first attempt, patients will need time and support to change;

- Develop a team approach to health promotion;

- Patients have a right to up-to-date, evidence-based preventive advice.

\section{Conclusion}

Promoting oral health is not a fruitless task, nor is it the idealistic vision many clinicians believe it to be. However, to get the best results we must approach it as a partnership, with our patients and with the wider community. All too often the practitioner has decided on what the patient's clinical need should be without due concern for his/her views, expectations and 'health' requirements. Unrealistic goals lead to disappointment for all parties, but our efforts can be effective when they are based on longterm supportive strategies rather than one-off events. The key message here is to involve the entire dental team and not to give up after the first attempt, as many individuals live with factors beyond their control. By building trust and confidence in your relationship and supporting them to take control of their health, real change 
is possible.

Finally, awareness of the social and environmental circumstances in which patients live, and by recognizing their competing interests, we are much better equipped to give appropriate and individual advice in a way that does not 'victim blame'. Oral health promotion is an integral component of this patient-centred, 'holistic' approach.

\section{Acknowledgements}

The author would like to express his thanks to Professor Liz Kay for her advice in the preparation of this manuscript.

\section{References}

1. Department of Health. Choosing Better Oral Health. An Oral Health Plan for England. London: HMSO, 2005.

2. Watt $R$, Sheiham A. Inequalities in oral health: a review of the evidence and recommendations for action. Br Dent $J$ 1999; 187: 6-12.
3. Marmot MG. Understanding social inequalities in health. Perspect Biol Med 2003; 46: 9-23.

4. Dahlgren $\mathrm{G}$, Whitehead M. Tackling inequalities: a review of policy initiatives. In: Tackling Inequalities in Health: An Agenda for Action. Benzeval M et al. Kings Fund, 1991.

5. World Health Organization. Constitution. Geneva: World Health Organization, 1946.

http://www.who.int/governance/ eb/who_constitution_en.pdf

6. Locker D. Concepts of oral health, disease and quality of life. In: Measuring Oral Health and Quality of Life. Slade G, ed. University of North Carolina, 1987.

7. Watt RG, Fuller SS. Oral health promotion - opportunity knocks! $\mathrm{Br}$ Dent J 1999; 186: 3-6.

8. World Health Organization. Ottawa Charter for Health Promotion. Can J Public Health 1986; 77: 425-430.

9. Sheiham A. Dental caries affects body weight, growth and quality of life in pre-school children. Br Dent $J$
2006; 201: 625-626.

10. National Institute of Clinical Excellence. Dental Recall: Recall Intervals between Routine Dental Examinations. London: NICE, 2004. Clinical Guideline 19.

11. Watt RG. From victim blaming to upstream action: tackling the social determinants of oral health inequalities. Community Dent Oral Epidemiol 2007; 35: 1-11.

12. Prochaska JO, DiClemente CC. Towards a comprehensive model of change. In: Progress in Behaviour Modification. Miller WR, Heather $\mathrm{N}$, eds. Sycamore: Sycamore Press, 1992.

13. Prochaska JO, Velicer WF. The transtheoretical model of behaviour change. Am J Health Promot 1997; 12: 38-48.

14. Martinelli E, Palmer RM, Wilson RF, Newton JT. Smoking behaviour and attitudes to periodontal health and quit smoking in patients with periodontal disease. J Clin Periodontol 2008; 35: 944-954.

\section{Book Review}

How to keep your TEETH FOR LIFE. The essential guide to healthy teeth for you and your family. By Dr Simon Riddle and Dr Hap Gill. Nutbourne Publications 2010 (138pp., £9.99 p/b). ISBN: 978-0-9564933-0-9.

Dr Riddle and Dr Gill, dentists with a passion for patient communication and aesthetic dentistry, have created a very easy-to-read book aimed at educating patients about all major areas of dentistry and maintaining oral health.

The book starts with information about tooth structure, advice on oral hygiene regimes and preventive care, then explores clinical aspects of dentistry as well as including sections on tooth whitening, the TMJ, wisdom teeth, common dental complaints and self help. Each section has clear, easy to understand diagrams and annotated photographs, including periodontal disease, which makes it easy for the reader to understand the subject. The authors discuss topics of importance to patients, such as tooth sensitivity, pregnancy in relation to dental care, longevity of restorative work and the use of mercury amalgam clearly and in an unbiased way. The book finishes with some useful website details. My only regret is that the book did not reference key guidance on key areas to expert published material such as the Faculty of General Dental Practitioner's (UK) guidance on antimicrobial prescribing and radiography or Delivering Better Oral Health published by the Department of Health, which would have given the book more credibility.

The book is easy to read and understand, clearly illustrated and, at $£ 9.99$ is exceptional value and, whilst aimed at patients and their families, is ideally suited for induction of new practice staff to all matters dental and, as such, I think it is a book that most practices should consider having a copy of for their library.

Alasdair G Miller GDP, Taunton

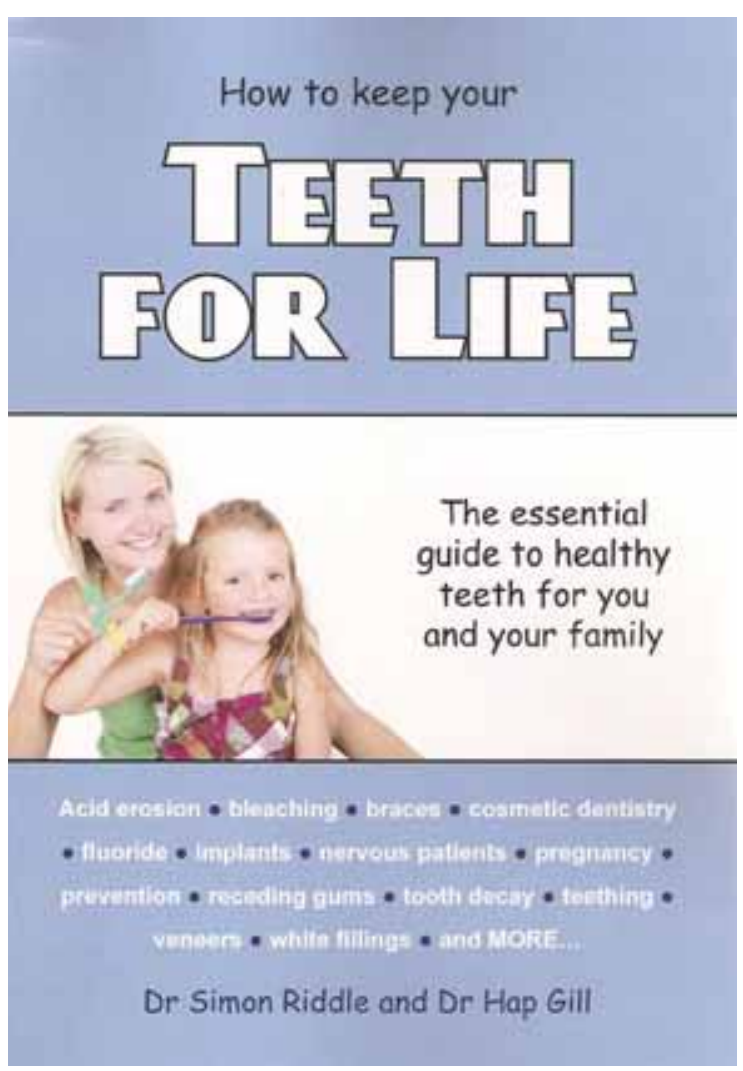

July/August 2010 